\title{
ESTROMATÓLITOS COLUNARES NA SÉRIE MINAS (MG)
}

\author{
MARCEL AUGUSTE DARDENNE* e MÁRIO DA COSTA CAMPOS NETO**
}

ABSTRACT Columnar algal stromatolites have been discovered in the Precambrian Minas Series, near the city of Cachoeira do Campo (Minas Gerais, Brazil). They appear in dolomite lenses intercalated in phyllites of the Piracicaba Group. These columnar stromatolites present convex laminae and two main types have been recognized:

Type A: thin high straight and subcylindroidal columns with ragged lateral surface and "passive" ramification.

Type B: irregular tuberous columns with "active" ramification.

Shallow quiet waters characterize the environment during the stromatolitic growth.

INTRODUÇÃo A ocorrência de estromatólitos colunares foi descoberta no início de novembro de 1974 na pedreira de Cumbi e Lapa, concessão da firma Enrico Guarnieri Indústria e Comércio S.A., que a explora para obtenção de pedras ornamentais desde 1935.

A referida pedreira se localiza a cerca de $10 \mathrm{~km}$ ao sul de Cachoeira do Campo, Estado de Minas Gerais. De Belo Horizonte, o acesso é feito através das rodovias BR-040 e MG-56 (entroncamento para Ouro Preto), tomando-se no quilômetro 71 desta última, antes da ponte sobre o Ribeirão Maracujá, estrada de terra patrolada que levará aos afloramentos Cumbi e Lapa (Fig. 1).

QUADRO GEOLOGICO REGIONAL Segundo Dorr II (1969), a divisão estratigráfica do Quadrilátero Ferrífero pode ser resumida conforme é apresentada na Tab. I.

Todas essas unidades são intensamente dobradas e falhadas. A idade da Série Minas é considerada (Dorr II, 1969) dentro do intervalo 1 350-1 000 m.a. a partir de datações geocronológicas obtidas pelo método K-Ar.

Ocorrência de estromatólitos colunares A ocorrência se situa no topo da Série Minas, no Grupo Piracicaba, e provavelmente pertence à Formação Fecho do Funil, apesar de esta não ter sido diferenciada por R. F. Johnson no mapa (1:25 000) das quadrículas de Dom Bosco e Ouro Branco, publicado por Dorr II (1969).

A Fig. 2 localiza os edifícios algais na geologia regional.

As construções aparecem nos dolomitos que constituem pequenas lentes nos filitos na Formação Fecho do Funil. Geralmente, essas lentes são envolvidas por filitos dolomíticos traduzindo uma passagem lateral e vertical de fácies em direção aos filitos não-carbonatados (Foto 1). Enquanto os filitos são intensamente microdobrados, a fácies dolomítica maciça não apresenta nenhum dobramento fechado. Da base da ocorrência até sua parte superior, todos os estromatólitos estão na posição original do seu crescimento, indicando claramente o topo da camada que possui uma atitude N50E, 30SE. A única e nítida deformação evidenciada é a ligeira e constante inclinação das colunas (N85E, 75SE), mais ou menos paralela à forte clivagem de fratura $(\mathrm{EW}, 75 \mathrm{~S})$, observada em todos os afloramentos de dolomitos e que corresponde à direção do plano axial do grande sinclinal de Dom Bosco (Fig. 2).

* Departamento de Geociências, Universidade de Brasília, Brasília, DF

**Metais de Minas Gerais S.A. (Metamig), rua Aimorés, 1697 , Belo Horizonte, MG 


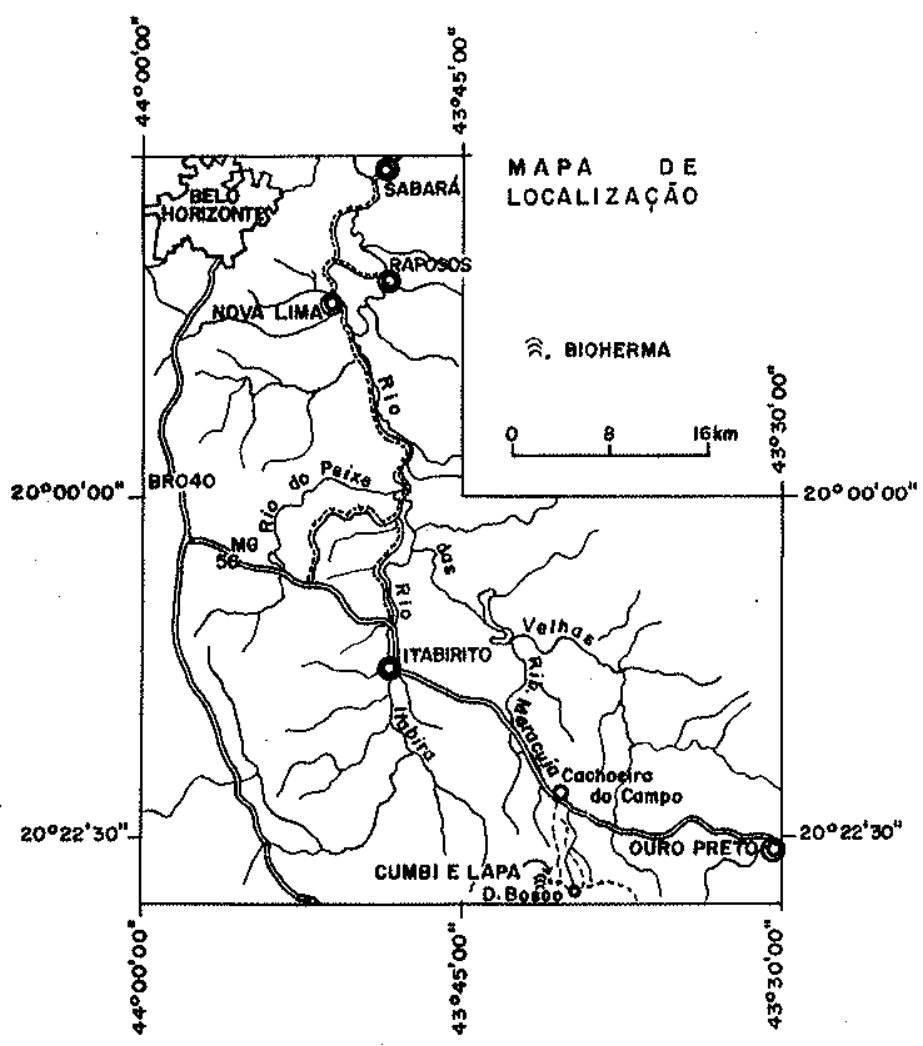

Figura 1

Tabela I

\begin{tabular}{|c|c|c|}
\hline SÉRIES & GRUPOS & FORMACYŌES \\
\hline 1 tacolomi & It acolomi & \\
\hline \multirow{4}{*}{ Minas } & Sabará & \\
\hline & $\begin{array}{c}\text { Pitacicaba } \\
\text { (OETRITICO - FLYSCH) }\end{array}$ & $\begin{array}{l}\text { Barreiro } \\
\text { Tabodes } \\
\text { Fecho do Funil } \\
\text { Cercadinho }\end{array}$ \\
\hline & $\begin{array}{l}1+a b i r a \\
\text { (auimico) }\end{array}$ & $\begin{array}{l}\text { Gandarela } \\
\text { Caue }\end{array}$ \\
\hline & $\begin{array}{c}\text { Cara\& a } \\
\text { (QUiMico-DETRítico) }\end{array}$ & $\begin{array}{l}\text { Batata I } \\
\text { Moed a }\end{array}$ \\
\hline Rio das Velhas & $\begin{array}{l}\text { Maquiné } \\
\text { Nova Lima }\end{array}$ & \\
\hline
\end{tabular}




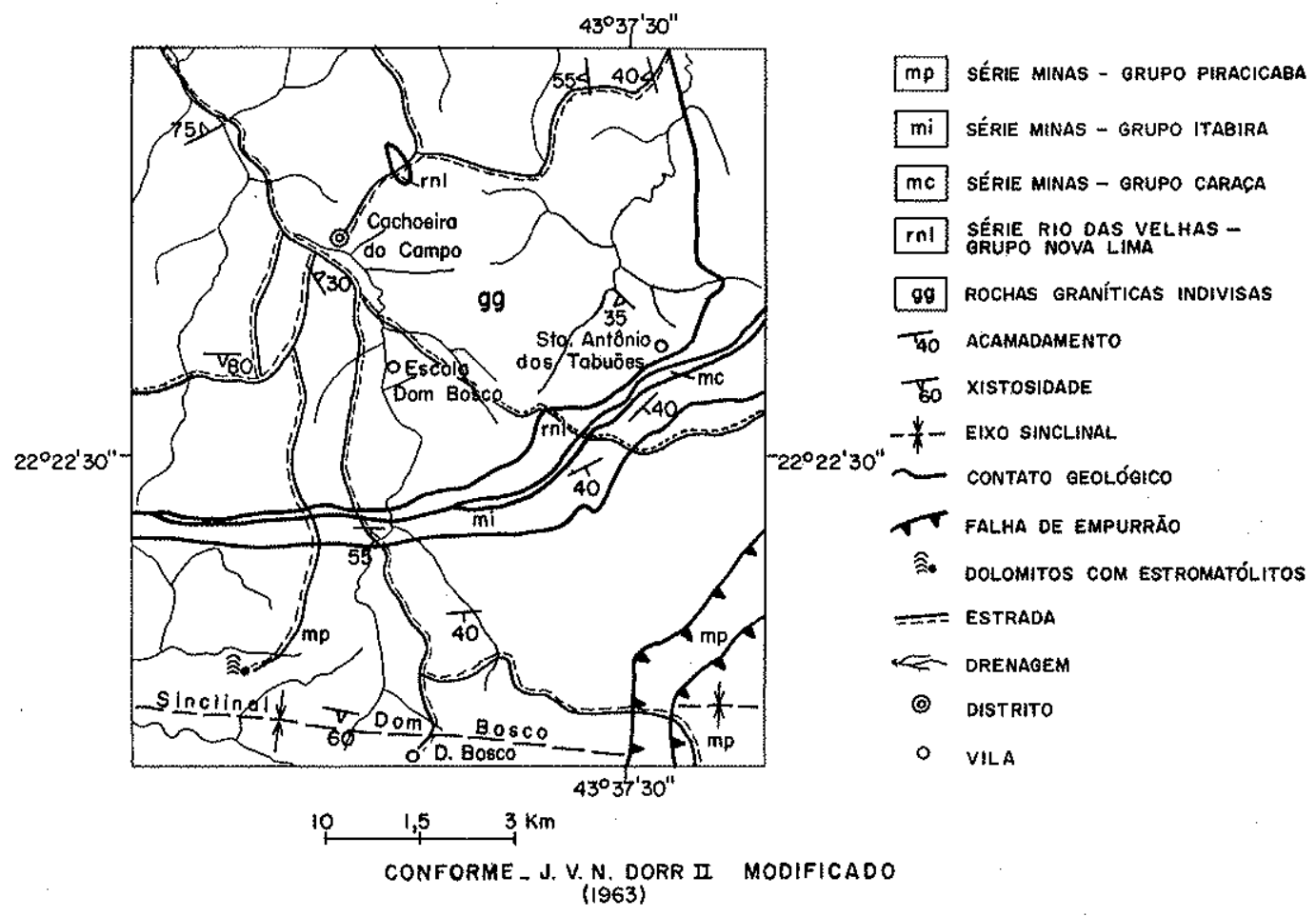

Figura 2 - Mapa de localização geológica

Foto 1 - Nivel inferior da sequiência dolomítica: dolomitos cinza com estromatólitos, sobrepostos por dolomitos bandados argilosos, mostrando parte da transição aos níveis menos carbonatados

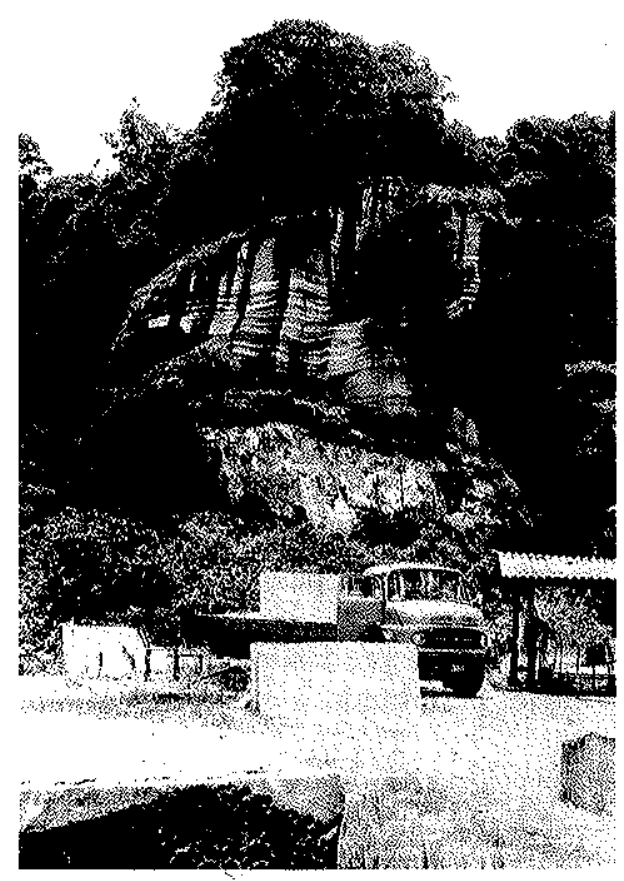




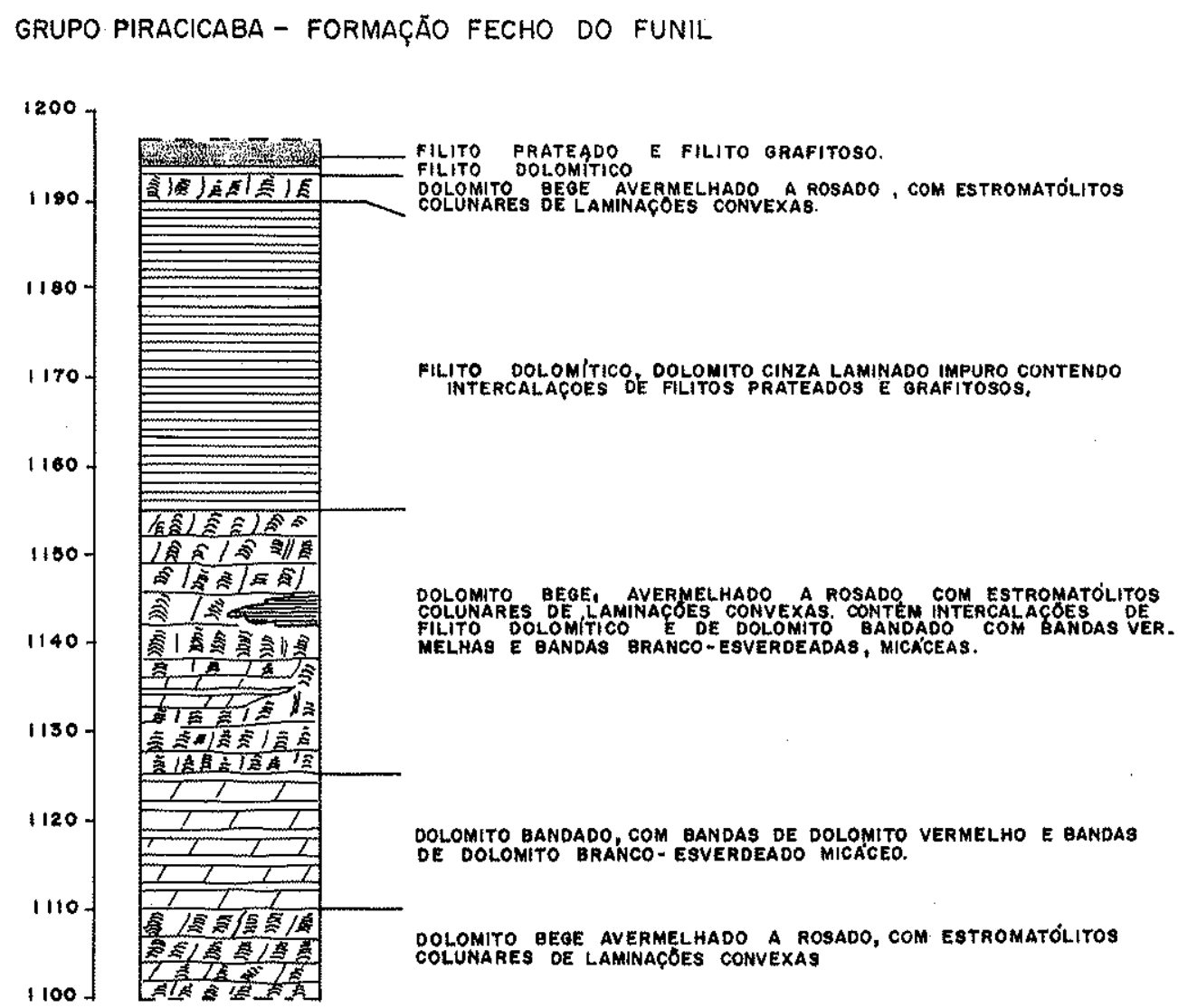

Figura 3 - Coluna estratigráfica simplificada da ocorrência de estromatólitos de Cumbi e Lapa (espessuras aparentes)

A estratigrafia sintética da ocorrência é resumida na Fig. 3. Nota-se a distribuição vertical dos estromatólitos colunares em três níveis distintos, sendo que os dois horizontes inferiores correspondem aos lavrados pela Companhia Enrico Guarnieri.

Estromatólitos colunares Os dolomitos contendo as construções algais são maciços e apresentam três colorações bem distintas: cinza-claro (particularmente na base); bege quase homogêneo, onde as colunas podem ser evidenciadas por fina película micácea e brilhante, localizada nos estilólitos, e que as separa entre si; vermelho-arroxeado a rosa, alternando com o bege.

Nos afloramentos, a presença dos estromatólitos é evidenciada pelas pequenas saliências produzidas pelo intemperismo na superficie áspera da rocha de cor bege a amarronzada.

Os cortes praticados para a obtenção das placas de mármore oferecem ótimas exposições permitindo o estudo das colônias algais em três dimensões.

Estromatblitos com laminą̧ões convexas Todas as construções algais da ocorrência se caracterizam por suas laminações convexas, empilhadas umas sobre as outras, formando colunas nitidamente separadas. 
A partir da morfologia dessas colunas, dois tipos de construções e, por conseqüência, dois tipos de estromatólitos, foram diferenciados:

Tipo A: Caracteriza-se por colunas finas e estreitas, ligeiramente onduladas, inclinadas paralelamente à clivagem de fratura que afetou a rocha dolomítica. A distância entre elas é muito pequena (de alguns milímetros a centímetros), mas podem atingir mais de $1 \mathrm{~m}$ de altura. $\mathrm{Na}$ superficie das placas de mármore, uma mesma coluna aparece descontinuamente. $O$ desaparecimento local da coluna e seu prosseguimento mais adiante, na mesma direção anterior, é interpretado como devido a pequenas ondulações e/ou aos cortes levemente oblíquos em relação a sua orientação (Foto 2). A largura das colunas (de 0,5 a $3 \mathrm{~cm}$ ) permanece mais ou menos constante em todos os afloramentos. Suas seções transversais (Foto 3) variam de circulares a formas ovais ou angulosas. As ramificações, raras, não conduzem a um espessamento geral das estruturas, sendo que as colunas-filhas permanecem paralelas à estrutura geral (Foto 3). A laminação é sublinhada, nos melhores casos, pela alternância de listras brancas e vermelho-arroxeadas (Foto 4) com uma forma convexa pouco acentuada, sem recobrimento. Somente em algumas exposições aparece uma laminação de forma subcônica, que é mais nítida na parte central da coluna, desaparecendo geralmente perto das bordas, isso porque a parte lateral é quase sempre de uma coloração avermelhada muito forte.

As laminações não formam pontes ligando uma coluna a outra, com exceção da zona inferior de seu desenvolvimento, onde elas podem ser similares a esteiras de algas a partir das quais se erigiram os pilares algais.

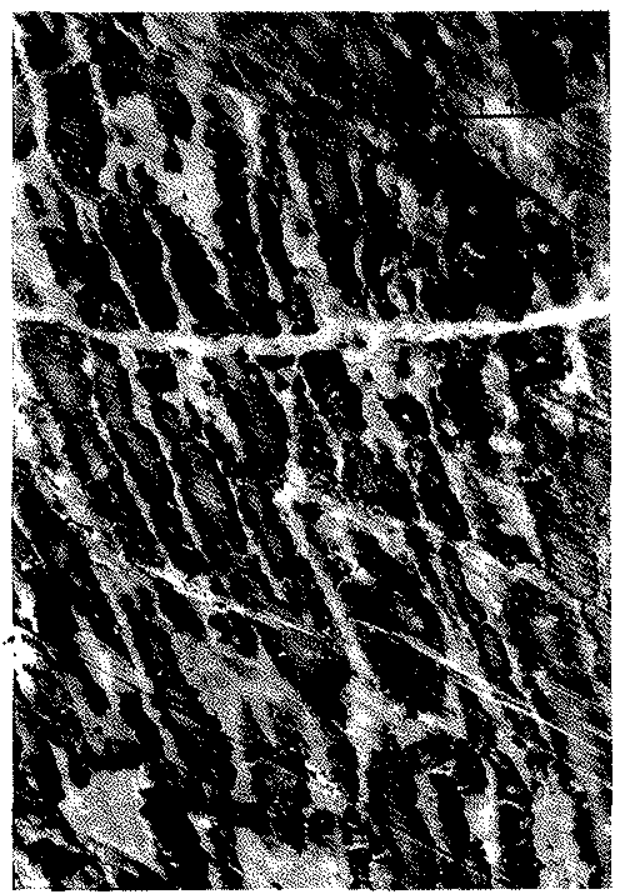

Foto 2 - Estromatólitos com laminações convexas: Tipo A, cortadas por veio de calcita. Nota: As estrias aparecendo na foto são conseqüência dos cortes efetuados para a obtenção das placas de mármore

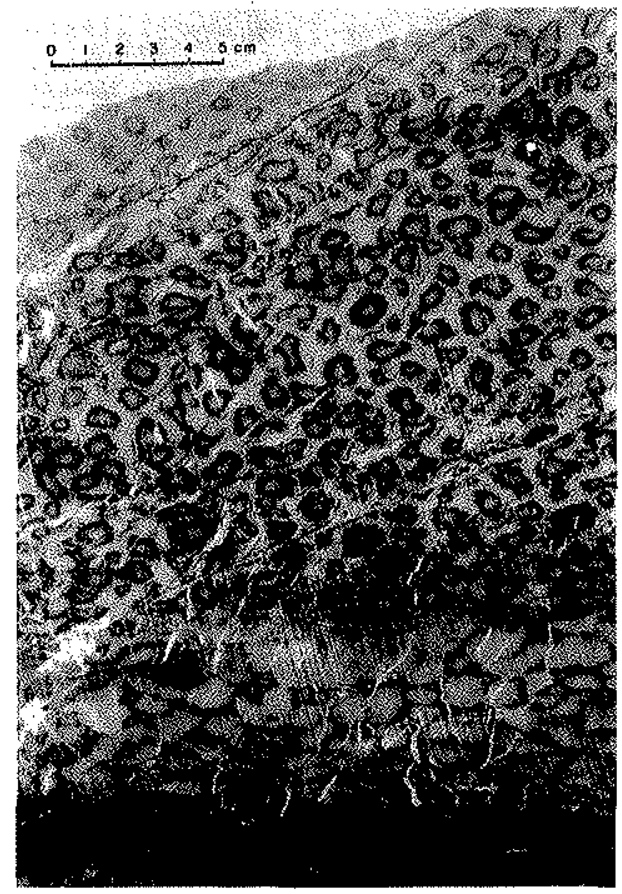

Foto 3 - Seção transversal dos estromatólitos com laminações convexas: Tipo A 
A superfície lateral das colunas que mostra numerosas saliências é sublinhada por óxidos de ferro. $O$ espaço entre as colunas, que é mínimo, é preenchido por um dolomito vermelho ou cinza-claro cristalino, muitas vezes quase imperceptivel.

A zona central das colunas é irregularmente recristalizada, o que faz com que as laminações, freqüentemente, sejam interrompidas. Por outro lado, as ondulações do eixo da coluna escondem irregularmente esta zona central, oferecendo a observação de formas extremamente alongadas, que sobretudo não devem ser confundidas com um estiramento (aqui inexistente) das seções transversais segundo o plano de xistosidade. Esta zona central, de bege a cinza, dá a aparência de uma pseudozona axial.

A microestrutura original se mostra apagada pela recristalização, o que compromete uma identificação mais precisa desses estromatólitos.

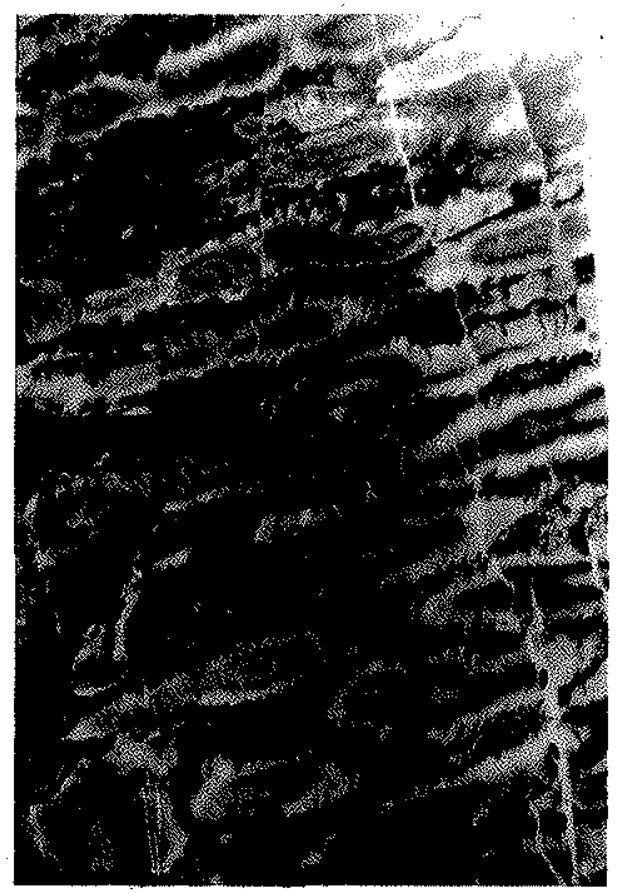

Foto 4 - Seção longitudinal dos estromatolitos com laminações convexas: Tipo A. Observar a alternância de faixas brancas e escuras que correspondem às laminaçzes originais (brancas e vermelho-arroxeadas)

Tipo B: Ocorre tanto nos dolomitos cinza da base, onde predomina, como nos dolomitos avermelhados do nível intermediário. Ao contrário do tipo precedentemente descrito, essas construções estromatolíticas se caracterizam por colunas mais largas (de 4 a $5 \mathrm{~cm}$ ), curtas (de 20 a $50 \mathrm{~cm}$ ) e tuberosas, com ramificações ativas, provocando uma expansão em direção ao topo da estrutura (Fig. 4). Numerosas e importantes protuberâncias se destacam sobre o fundo da rocha encaixante, de bege-claro-amarelada a cinza-clara. As seções transversais $(\varnothing 3 \mathrm{a} 6 \mathrm{~cm})$ são geralmente irregulares. $O$ limite lateral das colunas é nítido e as laminações convexas se recobrem pouco. Neste caso, também a microestrutura se mostra apagada pela recristalização.

CLASSIFICAÇÃO Segundo a classificação de Raaben (1969), que é baseada sobre a morfologia, o modo de ramificação, a forma das laminações e sobre a microestrutura das laminações, subdividem-se os estromatólitos colunares em Supergrupos, Grupos e Formas. 
No presente caso, nosso objetivo não passa de uma tentativa preliminar, antecipando-se à opinião de especialistas na matéria. Essas precauções se devem à exuberante morfologia dos estromatólitos colunares com laminações convexas e sobretudo ao fato de que a microestrutura, dado dos mais importantes, não foi conservada.

Assim, o Tipo A pode se enquadrar no Supergrupo dos Kussielides enquanto o Tipo B parece, sem dúvida, pertencer ao Supergrupo dos Tungussides e talvez ao Grupo Baicalia.

Este último, Grupo Baicalia, é geralmente considerado como característico da idade Rifeano Médio (1 350-950 m.a.). A confirmação posterior de tal determinação pode conduzir a certas implicações estratigráficas e geocronológicas extremamente importantes:

1. Seria o conjunto todo da Série Minas compreendido nesta faixa de idade? A discordância erosiva assinalada por Dorr II (1969) na base do Grupo Piracicaba pode cor* responder a um hiato de tempo cuja importância é de dificil avaliação. Uma parte da resposta reside sem dúvida nas fácies dolomíticas da Formação Gandarela, sotoposta ao Grupo Piracicaba, que pode conter construções algais que permitiriam ajudar na resolução deste delicado problema.

2. Seria esta idade conflitante com as últimas datações do Grupo Bambuí a partir de estruturas estromatolíticas? Ultimamente, o Grupo Bambuí vem sendo considerado por vários autores (Moeri, 1972; Cloud e Dardenne, 1973; Dardenne, inédito; Dardenne et al., inédito) como de idade Rifeano Médio, a partir do estudo de estromatólitos colunares. Enquanto Moeri prefere uma idade correspondendo à base do Rifeano Médio, Cloud e Dardenne, Dardenne, e Dardenne et al. são mais inclinados para uma idade próxima de $950 \mathrm{~m}$ :a. para o Grupo Bambuí. Esta última opinião nos parece mais provável e conduz a um quadro mais lógico no estado atual dos conhecimentos, onde o Grupo Piracicaba teria uma idade de cerca de 1350 m.a.

Evidentemente, essas considerações merecem um número maior de observações, em várias localidades e sobre diferentes tipos de estromatólitos.

Ambiente de sedimentação A presença desses bio-hermas de origem algal caracteriza um ambiente de sedimentação com águas rasas e calmas, conforme atesta a ausência de intraclastos e de feições erosivas na ocorrência estudada. Essas observações se opõem a uma sedimentação de tipo flysch proposta por Dorr II (1969) para o Grupo Piracicaba, pelo menos na parte inferior deste Grupo.

\section{BIBLIOGRAFIA}

CLOUD, P. E., Jr, e DARDENNE, M. A. - 1973 - Proterozoic age of the Bambur Group in Brazil, Geol. Soc. Am. Bull., 84: 1673-1976

DARDENNE, M. A. - Occurrence de stromatolites columnaires dans le Groupe Bambuí, Goiás, Brésil (em preparação)

DARDENNE, M. A., GAMPOS NETO, M. C. e BARREIRAS, C. F. - New occurrence of com lumnar stromatolites in the Precambrian Bambuí Group of Minas Gerais, Brazil (em preparação)

DORR II, J. V. M. - 1963 - Mapa Geológico e Seçð̃es do Quadrilátero Ferrífero, Minas Gerais, Brazil (1/150 000), DNPM e USGS

DORR II, J. V. M. - 1969 - Physiographic, stratigraphic an structural development of the Quadrilátero Ferrifero, MG, U.S.G. Survey, Prof. Paper 641A, 110 pp., Washington

MOERI, E. - 1972 - On a columnar stromatolite in the Precambrian Bambur Group of Central Brazil, Ecl. Geol. Helv., 65 (1): 185-195

RAABEN, M. E. - 1969 - Columnar stromatolites and late Precambrian stratigraphy, Am. Journ. Sc., 267: 1-18. 